\title{
Performance of concrete containing high volume coal fly ash - green concrete
}

\author{
C. Magureanu \& C. Negrutiu \\ Technical University of Cluj-Napoca, \\ Faculty of Civil Engineering, Romania
}

\begin{abstract}
Concrete is usually the most common element in a building and over the years, many solutions were developed in order to improve its qualities. We conducted a comparison between ordinary Portland cement concrete and high volume coal fly ash concrete, with the fly ash used as a substitute for the cement. Generally accepted, the total binder in a green concrete is composed of $50 \%$ cement and $50 \%$ fly ash, which is less than $200 \mathrm{~kg} / \mathrm{m}^{3}$ in our case (P. Kumar Mehta - High Performance, high-volume fly ash concrete for sustainable development. University of California, Berkeley, USA). We investigated concrete mixes containing $40 \%$ and $50 \%$ fly ash as partial replacements of the cement. A C20/25 class concrete was tested at 7, 28, 90 and 365 days of age for: compressive and tensile strength, modulus of elasticity, freeze thaw resistance, water permeability, and shrinkage and bond strength. We found that concrete made with fly ash is a good choice for a medium concrete class with increased durability properties.
\end{abstract}

Keywords: fly ash, compression, splitting, modulus, bond, freeze thaw, permeability, shrinkage.

\section{Introduction}

Concrete, usually composed of gravel, sand, water and Portland cement, is an extremely versatile building material. Unfortunately, significant environmental problems result from the production of the Portland cement, which is responsible for $6-7 \%$ of the total carbon dioxide $\left(\mathrm{CO}_{2}\right)$ produced by humans [1]. A waste product can be used as a substitute for large portions of the Portland cement, significantly improving concrete's environmental characteristics, as shown in previous research [2-5]. When mixed with lime and water, fly ash forms a 
compound very similar to Portland cement. If high volumes of fly ash are used in concrete, displacing more than $20 \%$ of the cement content, the environmental impact will be reduced and the durability of the concrete will be improved [1]. Furthermore, a more dense concrete, with smaller capillary pores would be obtained [6]. The addition of pozzolanic materials, such as fly ash, influences the concrete durability and also the mechanical properties, especially the compressive and tensile strength and the modulus of elasticity [3]. These properties are very important for structural design. The objective of this paper is to evaluate the effect of pozzolanic materials, especially fly ash, on the mechanical properties of the concrete.

\section{Experimental program}

Four concrete mixes were prepared and tested to evaluate the influence of the fly ash on the mechanical properties [2-5]. Experimental investigations were performed to assess the influence of the fly ash on the concrete. The cement was partially replaced by fly ash (40-50\%). A superplasticiser MAPEI $(1.3 \%$ of the cement mass) was combined with the mixing water, in order to obtain a normal consistency of the cement paste. Tests were performed to obtain the concrete density and strength and the water absorbing kinetics.

It was established from the tests that when replacing the cement with a major amount of fly ash, the water requirement increases, because of a large porosity and because of the specific surface of the fly ash.

Table 1: $\quad$ Mix proportions.

\begin{tabular}{|c|c|c|c|c|}
\hline \multirow[t]{2}{*}{ Mix } & \multicolumn{2}{|l|}{1} & \multicolumn{2}{|l|}{2} \\
\hline & $\mathrm{a}$ & $\mathrm{b}$ & $\mathrm{a}$ & $\mathrm{b}$ \\
\hline 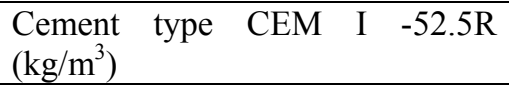 & 352 & 176 & - & - \\
\hline $\begin{array}{l}\text { Cement type CEM II/B-M(S-V) } \\
42.5 \mathrm{~N}\left(\mathrm{~kg} / \mathrm{m}^{3}\right)\end{array}$ & - & - & 361 & 216 \\
\hline Gravel $\left(\mathrm{kg} / \mathrm{m}^{3}\right)$ & 1025 & 1025 & 1096 & 1096 \\
\hline Sand $\left(\mathrm{kg} / \mathrm{m}^{3}\right)$ & 723 & 723 & 916 & 916 \\
\hline Fly ash $\left(\mathrm{kg} / \mathrm{m}^{3}\right)(\%)$ & - & $\begin{array}{l}176 \\
(50 \%)\end{array}$ & - & $\begin{array}{l}145 \\
(40 \%)\end{array}$ \\
\hline Water $\left(1 / \mathrm{m}^{3}\right)$ & 167 & 167 & 217 & 217 \\
\hline $\mathrm{W} / \mathrm{B}$ & 0.47 & 0.47 & 0.60 & 0.60 \\
\hline Superplasticiser $\left(\mathrm{ml} / \mathrm{m}^{3}\right)$ & 4600 & 4600 & 5200 & 5200 \\
\hline
\end{tabular}

\subsection{Material properties}

The cement used was Portland cement CEM I -52.5R and CEM II/B - M(S-V) $42.5 \mathrm{~N}$. River gravel (Aghires) with a maximum size of $16 \mathrm{~mm}$ was used as a coarse aggregate and river sand as the fine aggregate. The pozzolanic material was fly ash with the specific gravity of 2.5 and the size of the particles ranging 
from 1 to 100 microns. The fly ash was also characterized by a high silica and high alumina content. Other admixtures consisted of water-reducing agents. The mix proportions are presented in Table 1.

The aggregates were added in the mixer with one half of the water requirement. The cement came next (after 90 seconds) and was followed by the pozzolanic materials. The concrete was mixed in the mixer with all the ingredients for 6 minutes. Later, the rest of the water and the superplasticiser were added and the mix was allowed to homogenize for 3 to 4 minutes. The batch was placed in cubes and prisms and vibrated to homogenize. The cubes and prisms were removed from the formwork after 24 hours and the specimens were cured in water until the age of seven days. For each mix, approximately 30 specimens were prepared and tested.

\subsection{Experimental methods}

The compressive strength tests were made in accordance to RILEM. Six cubes of $150 \times 150 \times 150 \mathrm{~mm}$ were tested for strength, $\mathrm{f}_{\mathrm{c}}$ at 7, 28 and 90 days and another six cubes were tested for splitting tensile strength $\mathrm{f}_{\mathrm{ct}, \mathrm{sp}}$ at 7,28 and 90 days. Also, six prisms were tested for the modulus of elasticity at 7,28 and 90 days.

The tests for the strengths and the modulus of elasticity were performed on the same day, using Advantest testing machine. The strain was measured using two digital dial gages attached on opposite sides, around the perimeter of the specimen. The prisms were loaded to a maximum stress equal to $40 \%$ of the maximum compressive strength, according to RILEM. The loading rate was constant at $0.2-0.25 \mathrm{MPa} / \mathrm{s}$. The compressive strength was also tested on cubes of $100 \times 100 \times 100 \mathrm{~mm}$, subjected to 100 cycles of freezing and thawing.

The water permeability was determined on cubes of $200 \times 200 \times 200 \mathrm{~mm}$, after being subjected to an increasing pressure up to 8 atmospheres.

The shrinkage was monitored on prisms of 100x100x550 and cylinders of $\Phi 90 \times 300 \mathrm{~mm}$. The specimens were kept in constant conditions of $60 \pm 5 \%$ relative humidity and $20 \pm 2^{0}$ temperature. The deformations were measured with the Huggenberger device, with the precision of $0.0001 " / 10 "$, starting from first day after casting and up to 90 days.

\section{Test results}

\subsection{Mechanical properties}

The investigation results are shown in Table 2.

The investigation results show that the compressive and tensile strengths are decreasing when a high percentage $(40-50 \%)$ of the cement is replaced by thermal-electrical fly ash (Table 2). However, the strengths are sufficient for a medium class of concrete. One can observe that the compressive strength decreases with $30 \%$ and the modulus of elasticity decreases with $10-15 \%$ for the concrete mix that contains $40 \%$ and $50 \%$ fly ash replacement. A decrease of 
Table 2: $\quad$ Properties of concrete with and without fly ash.

\begin{tabular}{|c|c|c|c|c|c|c|c|}
\hline \multirow{3}{*}{$\begin{array}{c}\text { Properties of } \\
\text { concrete }\end{array}$} & \multirow{3}{*}{$\begin{array}{c}\text { Age } \\
\text { (days) }\end{array}$} & \multicolumn{6}{|c|}{ Mix } \\
\hline & & \multicolumn{3}{|c|}{1} & \multicolumn{3}{|c|}{2} \\
\hline & & $\mathrm{a}$ & $\mathrm{b}$ & $\mathrm{b} / \mathrm{a}$ & $\mathrm{a}$ & $\mathrm{b}$ & $\mathrm{b} / \mathrm{a}$ \\
\hline \multirow{3}{*}{$\begin{array}{l}\text { Compressive } \\
\text { strength }-\mathrm{f}_{\mathrm{cm}} \\
(\mathrm{MPa})\end{array}$} & 7 & 55.30 & 40.40 & 0.73 & 43.12 & 25.10 & 0.58 \\
\hline & 28 & 64.90 & 50.60 & 0.78 & 54.70 & 35.50 & 0.65 \\
\hline & 90 & 67.59 & 62.40 & 0.92 & 64.80 & 46.70 & 0.72 \\
\hline \multirow{3}{*}{$\begin{array}{l}\text { Splitting tensile } \\
\text { strength }-\mathrm{f}_{\mathrm{ct}, \mathrm{sp}} \\
(\mathrm{MPa})\end{array}$} & 7 & 4.60 & 3.10 & 0.70 & 3.00 & 2.00 & 0.67 \\
\hline & 28 & 5.50 & 3.30 & 0.60 & 3.50 & 3.10 & 0.88 \\
\hline & 90 & 5.70 & 3.70 & 0.65 & 3.90 & 3.50 & 0.90 \\
\hline \multirow{3}{*}{$\begin{array}{l}\text { Modulus of } \\
\text { elasticity }-\mathrm{E}_{\mathrm{cm}} \\
(\mathrm{GPa})\end{array}$} & 7 & 42.05 & 34.09 & 0.81 & 37.33 & 32.72 & 0.87 \\
\hline & 28 & 43.35 & 40.13 & 0.92 & 40.80 & 34.17 & 0.84 \\
\hline & 90 & 44.55 & 41.11 & 0.92 & 42.29 & 35.63 & 0.84 \\
\hline \multirow[t]{3}{*}{$\begin{array}{l}\text { Freeze-thaw } \\
\mathrm{f}_{\mathrm{cm}}(\mathrm{MPa})\end{array}$} & $\begin{array}{l}\text { Witness } \\
\mathrm{f}_{\mathrm{cm}} \mathrm{m}\end{array}$ & 59.35 & 52.60 & 0.88 & 58.25 & 44.75 & 0.78 \\
\hline & $\begin{array}{l}\text { After } \\
100 \\
\text { cycles } \\
\mathrm{f}_{\mathrm{cm}} 100\end{array}$ & 66.42 & 54.10 & 0.82 & 54.57 & 40.90 & 0.75 \\
\hline & $\begin{array}{l}f_{c m}{ }^{100} / \\
f_{c m}\end{array}$ & 1.12 & 1.03 & - & 0.937 & 0.914 & - \\
\hline
\end{tabular}

$3-5 \%$ in compression strength is also observed after 100 cycles of freezing and thawing, compared to the witness specimens (Table 2).

\subsection{Water permeability results}

The concrete containing fly ash (mix $1 \mathrm{~b}$ and $2 \mathrm{~b}$, Table 3 ) proved a higher permeability to water under pressure than ordinary cement based concrete (mix $1 \mathrm{a}$ and $2 \mathrm{a}$, Table 3 ).

Table 3: $\quad$ Water permeability.

\begin{tabular}{|l|l|l|l|}
\hline Mix & & Water penetration depth $(\mathrm{mm})$ & $\mathrm{f}_{\text {ct,sp }}(\mathrm{MPa})$ \\
\hline \multirow{3}{*}{1} & $\mathrm{a}$ & 0 & 3.39 \\
\cline { 2 - 4 } & $\mathrm{b}$ & 40 & 3.20 \\
\hline \multirow{2}{*}{2} & $\mathrm{a}$ & 0 & 3.48 \\
\cline { 2 - 4 } & $\mathrm{b}$ & 30 & 2.30 \\
\hline
\end{tabular}

\subsection{Shrinkage}

The shrinkage of the concrete is directly influenced by the presence of the fly ash in the mix. One can notice a more significant shrinkage in the mixes with zero content of fly ash (Figure 1). 


\subsection{Bond strength}

Previous research [7] shows that a friction bond between fibers and concrete is improved by the presence of fly ash.
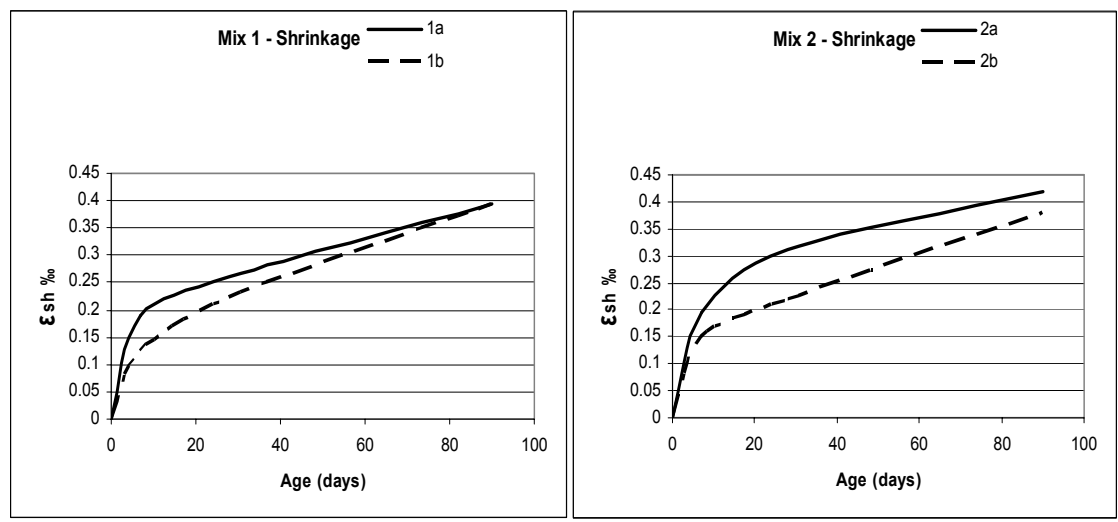

Figure 1: $\quad$ Influence of fly ash on the shrinkage of mix 1 and mix 2 .

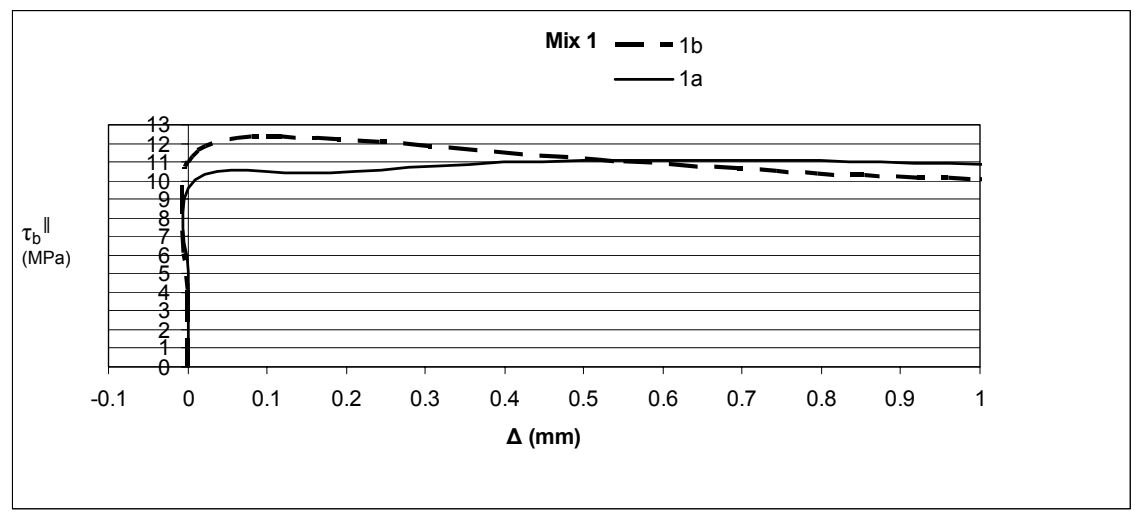

Figure 2: $\quad$ Bond strength $\tau^{\|}$and $\Delta$ at 28 days.

Figures 2 to 5 illustrate the influence of the fly ash on the bond strength of the concrete on mix 1 and 2 . The presence of the fly ash improves the quality of the concrete in terms of bond strength between the concrete and a round steel bar, as the fine particles fill the pores of the concrete, creating a denser microstructure. Furthermore, the mix with $50 \%$ replacement of the cement by fly ash (mix 1) developed higher bond strength than the one containing 40\% fly ash (mix 2). Mix 1 performed better than mix 2 by $24 \%$ for parallel bond (Figures 2 and 4 ) and $7 \%$ for perpendicular bond (Figures 3 and 5). 
378 Computational Methods and Experiments in Materials Characterisation IV

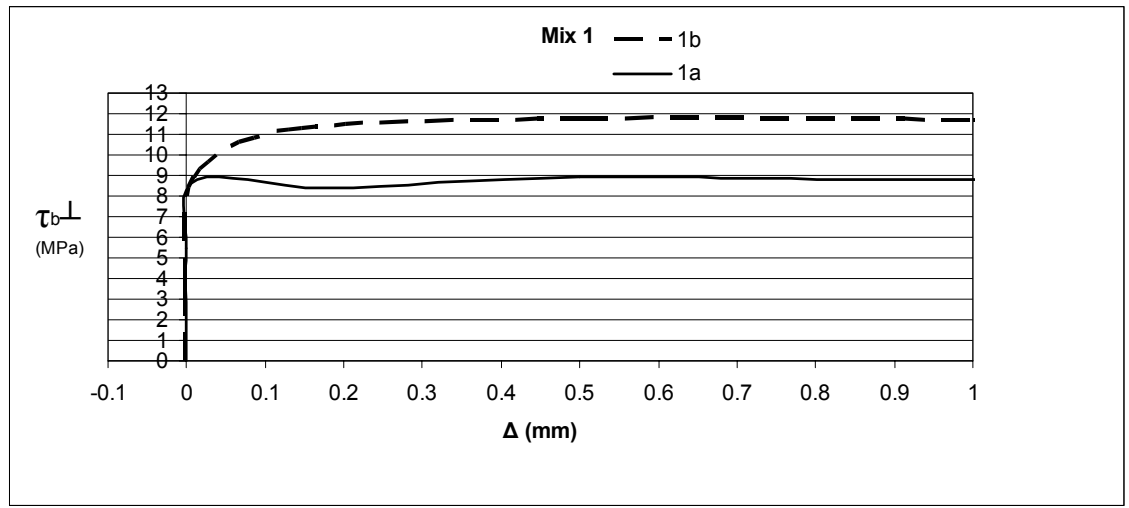

Figure 3: $\quad$ Bond strength $\tau^{\perp}$ and $\Delta$ at 28 days.

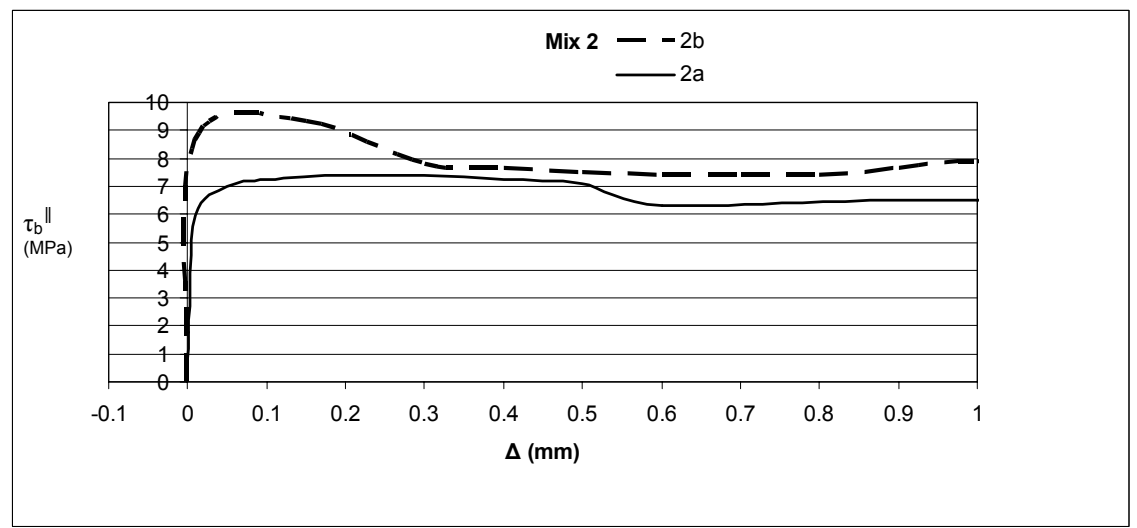

Figure 4: $\quad$ Bond strength $\tau^{\|}$and $\Delta$ at 28 days.

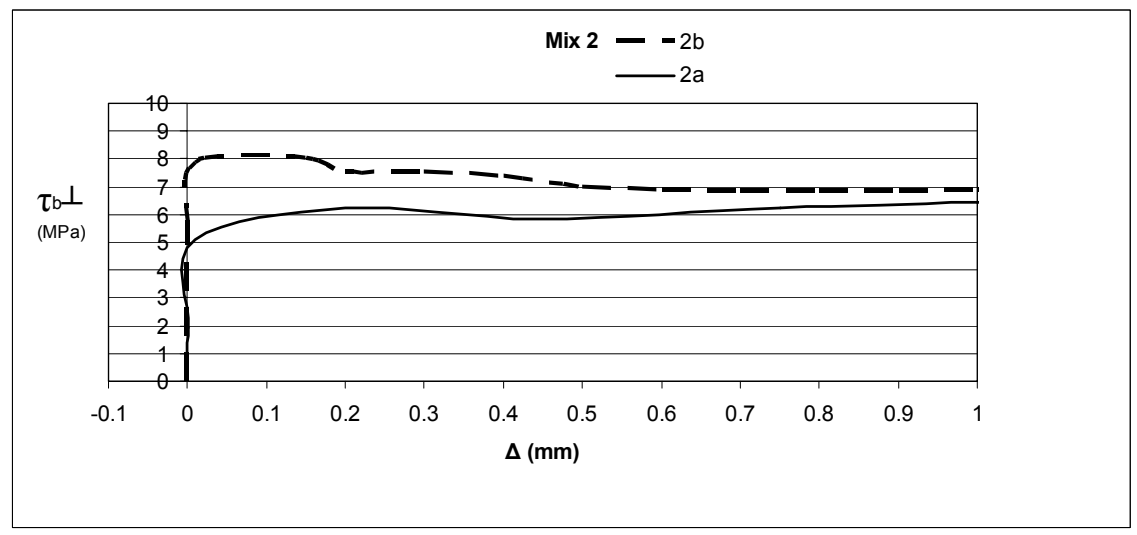

Figure 5: $\quad$ Bond strength $\tau^{\perp}$ and $\Delta$ at 28 days. 


\section{Conclusions}

Fly ash increases the workability of the concrete. Used as a partial binder, fly ash leads to sufficiently high properties for small and medium compressive strength classes of concrete in respect to compressive strength and tensile strength, although the strengths decrease by approximately $30 \%$. A smaller percentage of $15 \%$ represents the influence of the fly ash on the modulus of elasticity (Table 2).

When subjected to harsh environmental condition as freeze-thaw cycles, high volume fly ash concrete (Table 2) will not significantly diminish its properties.

The shrinkage (Figure 1) and the bond strength (Figures 2 to 5) prove a good behavior of the green concrete, compared to the ordinary concrete, which is consistent with previous studies.

However, water permeability is higher in the green concrete than in ordinary concrete and the concrete mixes will be revised on that matter.

Our results show that the use of fly ash as a cement replacement in certain quantities will produce a green concrete of medium class, less precarious for the environment than ordinary concrete, with good durability properties.

\section{References}

[1] P. Kumar Mehta - High Performance, high - volume fly ash concrete for sustainable development. University of California, Berkeley, USA.

[2] Cornelia Magureanu, Camelia Negrutiu, Ioan Sosa - Green concreteMechanical Properties, Proceedings Jubilee International SCIENTIFIC CONFERENCE VSU'2008, May 29 - May 30, 2008, Sofia, Bulgaria, Vol. II, ISBN 978-954-331-020-3

[3] Cornelia Magureanu, Camelia Negrutiu - Effect of fly as on the mechanical properties of concrete, International Symposium "Mineral resources and Environment Engineering”, Baia Mare, Romania, 24-25 October 2008, ISBN 978-973-1729-74-9

[4] Cornelia Magureanu - Effect of fly ash on the mechanical properties of concrete. Sustainable development in the Balkan Area: Vision and reality. Proc. of the Conference B.E.N.A. - ICAI 2007, Alba Iulia, 18-20 July p. 98 ISBN 978-973-7942-88-3

[5] Cornelia Magureanu - Betonul verde - perspective de viitor. Comportarea in situ a constructiilor. Conf. Nat. cu participare internationala Ed. XV, Bucuresti, 22-24 Sept. 2004, pp. 27-30

[6] Barzin Mabasher, Alva Peled, Jitendra Pahilajani - Pultrusion of Fabric Reinforced High Fly Ash Blended Cement Composites. Proc. RILEM Technical Meeting, BEFIB, 2004, pp. 1473-1482.

[7] Shuxin Wang, Victor C. Li - Engineered Cementitious Composites with High-Volume Fly Ash. ACI Materials Journal. May-June 2007, pp. 233-241. 